\title{
Research on Art Intervention in Rural Design Based on the Cultural Ecology: A Case Study of the Xun Jiansi Village in Jiangxi Province, China
}

\author{
Wang Mengqi ${ }^{1}$ \\ ${ }^{1}$ College of Fashion and Art Design, Dong Hua University, Shanghai, China \\ Correspondence: Wang Mengqi, College of Fashion and Art Design, Dong Hua University, Shanghai, China. \\ E-mail: 18800299827@163.com
}

Received: October 12, 2021

Accepted: November 3, $2021 \quad$ Online Published: November 29, 2021

doi:10.5539/ass.v17n12p55

URL: https://doi.org/10.5539/ass.v17n12p55

\begin{abstract}
In 2021, the world will enter the post-epidemic era. China is at the end of the 13th Five-Year Plan for the integration of urban and rural development and rural revitalization. At the same time, the internal circular economy brings opportunities for rural development and regional revitalization. This article uses interdisciplinary research methods, integrates various design models involved in cultural ecology, and strengthens the connections between them, combined with innovative thinking in rural design, art promotion, cultural inheritance, and industrial upgrading paths. The article intends to solve how to use environmental art and public Art, experimental art and other art forms are involved in rural design, and based on the theoretical framework of cultural ecology, the rural design method is constructed through the case analysis of the Xun Jiansi village, and the innovative and characteristic development path of art intervention in rural design is studied.
\end{abstract}

Keywords: design study, rural design, artistic intervention, cultural ecology, case study

\section{The Research Status of Rural Design and Cultural Ecology}

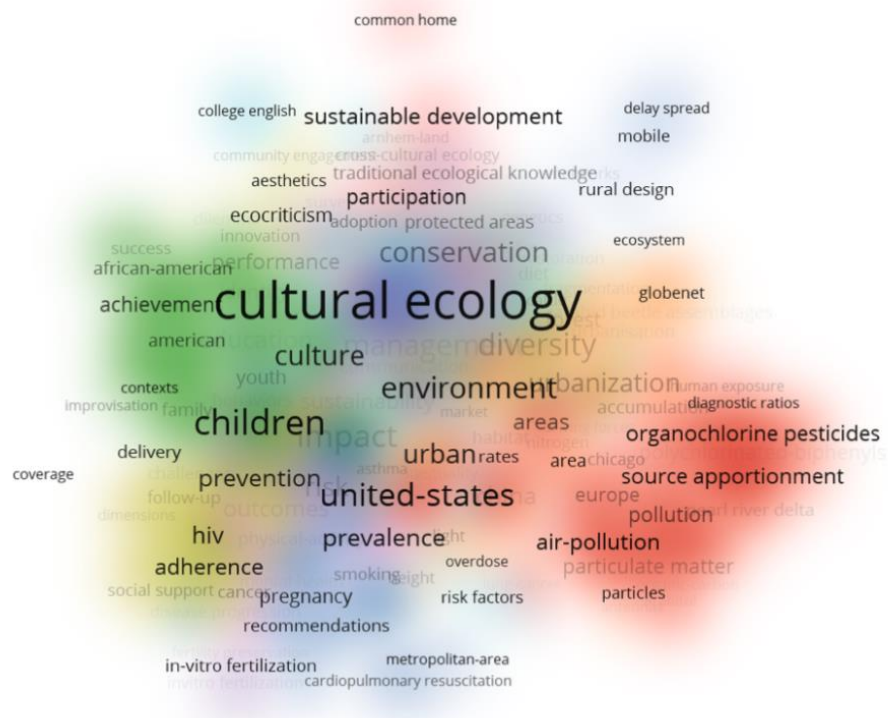

Figure 1. Keywords thermal analysis diagram

The openness and democratic characteristics of the design discipline are the advantages of design participating in rural construction. This study adopts scientometric methods, selects relevant documents from 5 commonly used citation index databases such as SSCI as the data basis, and analyzes the domestic and foreign rural design research papers with the assistance of information visualization Citespace software and Endnote document management software. Use the Web of Knowledge (WOK) retrieval platform's Web of Scienc core set (SSCI, SCI-Expanded, A\&amp, HCI, CPCI-S and CPCI-SSH) commonly used 5 citation indexes as data sources. The 
document collection time is until May 2021. On the 12th, affected by the database to retrieve data from 1984 to the present, research trends, research hotspots and subject areas, in order to ensure the comprehensiveness and accuracy of the sample data, after many retrieval experiments, the final search term was set to, Rural design, Cultural Ecology,or ,Art intervention.The search terms are limited to the,Title, field. The addition of search lines restricts the document types to Article (article) and Proceedings Paper (conference paper). After manually deleting inconsistent documents, a total of 1143 representative papers are retrieved.tion, and evaluation of social improvement and poverty elimination.

Highlight the main structural features of the subject and perform keyword cluster analysis on keywords. The high-frequency words used in rural design research include cultural ecology, children, environment, conservation, art, etc. Keywords, further clarify the hotspot direction of rural design research.

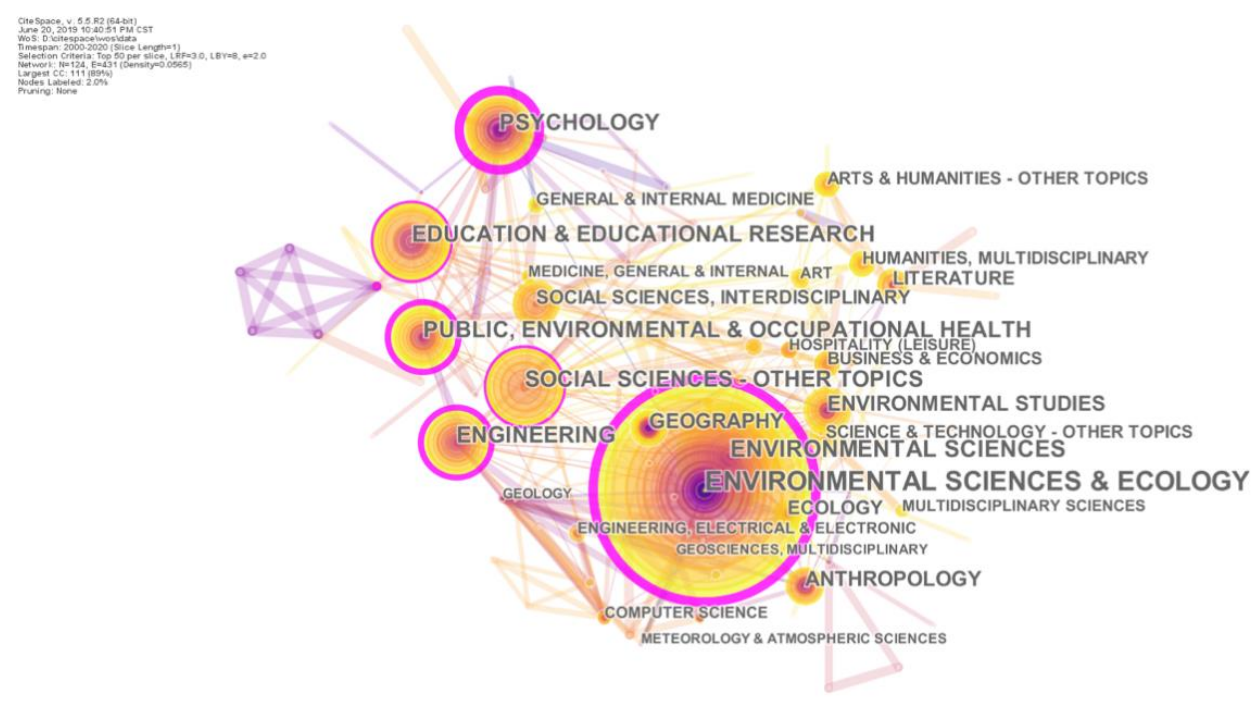

Figure 2. Subject Co-occurrence Map

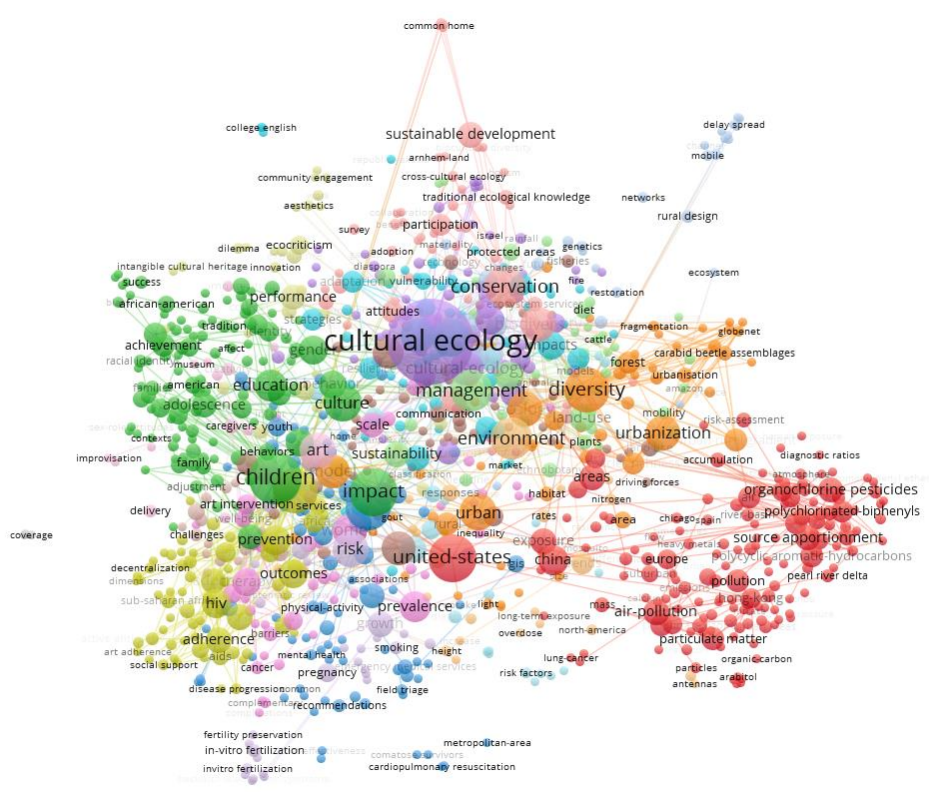

Figure 3. Keyword cluster analysis graph

Considering from the two dimensions of clustering and time, the research hotspots of the subject can be summarized into three clusters: innovative development of rural urbanization, cultural and ecological sustainability, rural environmental art design, and embodying culture, ecology, and humanities. The three aspects of art research are closely related. Through the analysis of the knowledge map of the research literature of rural design in the past 40 years, it is found that the research progress of this subject is very significant, and a batch of solid classics have been formed. Mainly reflected as follows: First, the current rural design research scholars have strong cross-border cooperation research. Second, the research on rural design mainly comes from 56 
countries (regions), and the number of publications in China ranks among the top in the world. Third, the research papers of rural design have rich topics, obvious interdisciplinary features, diverse research perspectives, and a total of 1132 keywords. Fourth, the study of rural design reflects the characteristics of the combination of macro and micro, theory and practice.

\section{Research on the Deduction of Cultural and Ecological Expression Methods of Rural Design}

In the modern transformation of Chinese society, the countryside has paid a heavy price. Back in the 1930s, intellectual elites represented by Mr. Liang Shuming, etc., dig deep into traditional resources and launched a vigorous rural construction movement. Once the urban and rural economic and cultural traditions are broken, the rural local autonomous units will be completely destroyed, and the Chinese villages washed by the torrent will naturally not escape the fate of defeat.

In the era of knowledge economy in the 21st century, the global industrial structure has undergone new adjustments, and creative industries are regarded as the standard and main direction of the new economy. As an emerging form of business, the creative industry is inevitably closely related to culture, technology, consumption, fashion and other elements. At present, China' s rural design is ushering in a micro-renewal stage. China is represented by developed regions and the needs of different villages in culture and form are differentiated., The transformation from planning of large-scale villages and characteristic towns to small-scale village groups and communities. Countries around the world have begun to implement rural reform strategies in response to rural problems: Japan-"one village, one product" regional resource regeneration; South Korea-the national driving force for rural modernization; Germany-maintaining the renewal planning of characteristic villages; the Netherlands-taking into account agricultural development And the beautification of the rural landscape; Britain-the dynamic balance of rural culture, environmental protection and economic development.

Scholars from Chiba University Miyazaki in Japan proposed eight indicators of internally developed township construction: 1) Focus on residents and daily life; 2) Pursue the activation of potential resources in the region; 3) Take the entire village and all residents as the main part Goals; 4) Carry out development related to basic needs; 5) Improve natural ecology; 6) Pursue cultural independence as the goal; 7) Promote the sense of integrity of the regional community; 8) Be based on technology that local residents can engage in.

This article uses the design method of art to intervene in the countryside to achieve the purpose of building a beautiful countryside. Through investigating the status quo of rural cases in China and consulting a large number of front-end academic papers, there are currently many restrictions on rural reconstruction in China, such as limited road traffic location factors, lack of community service education functions, lack of local art education in primary and secondary schools, lack of local culture, and hollowing out of the countryside Homesickness is reduced, artistic craftsmanship is declining, excessively artificial natural landscapes, conflicts between new and old buildings, protection of old houses and old sites, and the promulgation of land laws. By referring to the limiting factors in the analysis elements of individual organisms in individual ecology, it lays a convenient basis for analyzing the complex relationship between organisms and the environment; it helps to grasp the essence of the problem and find the weak link to solve the problem.

\section{Case Analysis of Xun Jiansi Village in Jiangxi Province, China}

The selected cases in this chapter are located in the northwest of Wuyuan, with Tsinghua Town to the east, Fuchun Town to the west, Gutan Township to the north, and Zhongyun Town to the south to be the only way from Tsinghua to Jingdezhen. The village was named after an official from the inspection department appeared in the ancient village. Its architectural style is based on Huizhou architecture. The inspection of Si Village has initially carried out architectural construction and landscape planning. Team members: Professor Feng Xinqun, Associate Dean of School of Fashion and Art Design, Donghua University, Doctoral Supervisor, Professor Liu Xiaodong, Associate Professor Zhao Qiang, Professor Yu Kongjian, School of Architecture and Landscape Design, Peking University, Yu Jinggan, academician of the United Nations International Academy of Ecological Life Safety Sciences, and a team of masters degree students in design, local artists, etc.

With the design concept of looking at the mountains, looking at the water and looking at life, art is implanted in the countryside, and art intervenes in a bold experiment in rural design. Outstanding results: The honeycomb hotel next to the rice field, the porcelain paintings in the alleys of the village entrance, the integration of porcelain and watercolor collide with a large number of art works, and the 5G Smart Village Art Life Aesthetics Museum, which uses the latest media technology to develop, will be launched on August 2020. Successfully held a 5G online exhibition in May, inviting artists from all over the world to visit ancient towns and villages online and create works of art together. 


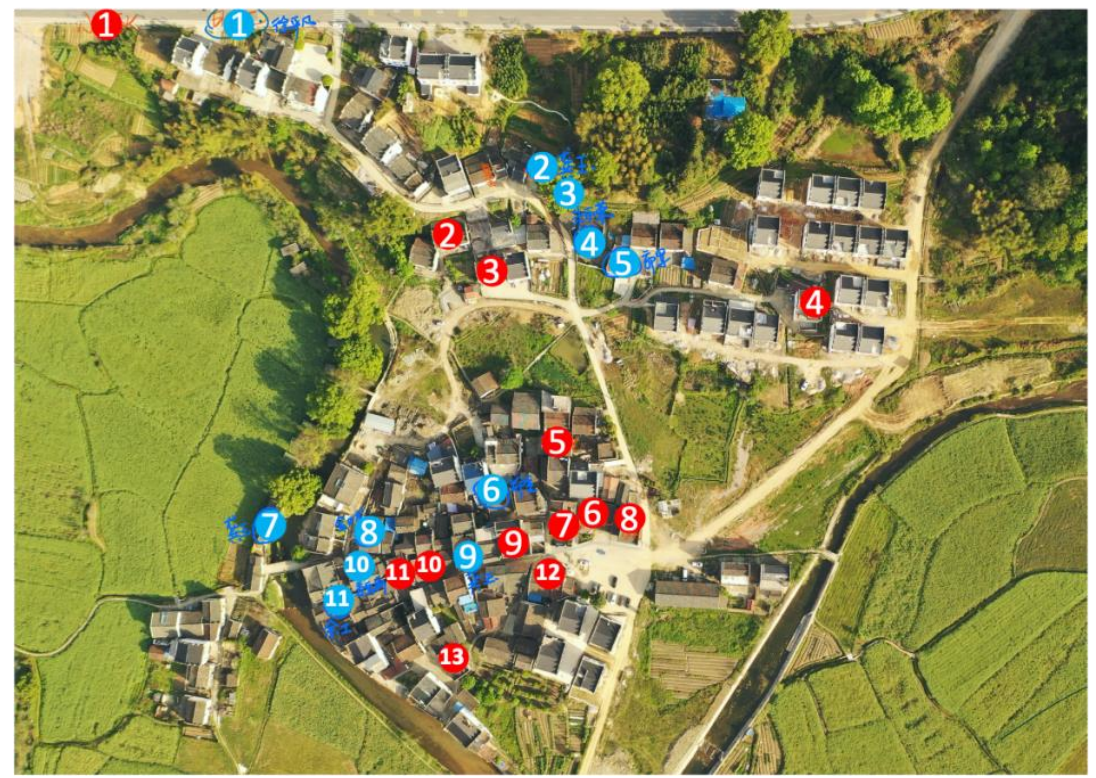

Figure 4. Xun Jiansi Village in Jiangxi Province, China

Table 1. Analysis of the cultural niche of art intervention in rural design

Analysis on the Cultural Ecology Niche of Art
Intervention Village $\begin{gathered}\text { Leading factors: Natural Environment, Man-made Environment, Cultural } \\ \text { Environment }\end{gathered}$

$\begin{array}{cc}\begin{array}{c}\text { 1. Cultural } \\ \text { Ecology } \\ \text { Niche }\end{array} & \begin{array}{c}\text { Natural environment: flat t } \\ \text { surrounded by farmland } \\ \text { village }\end{array} \\ & \begin{array}{c}\text { Traditional space and count } \\ \text { 2. Limiting }\end{array} \\ \text { Factors } & \end{array}$

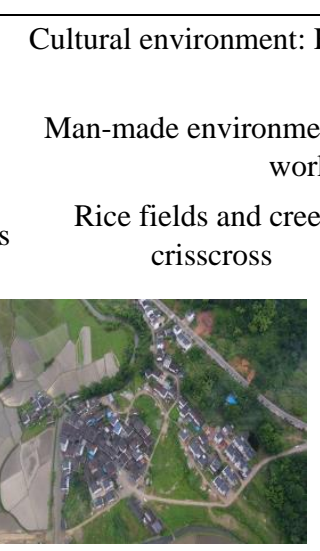
Environment

\section{Anhui style houses}

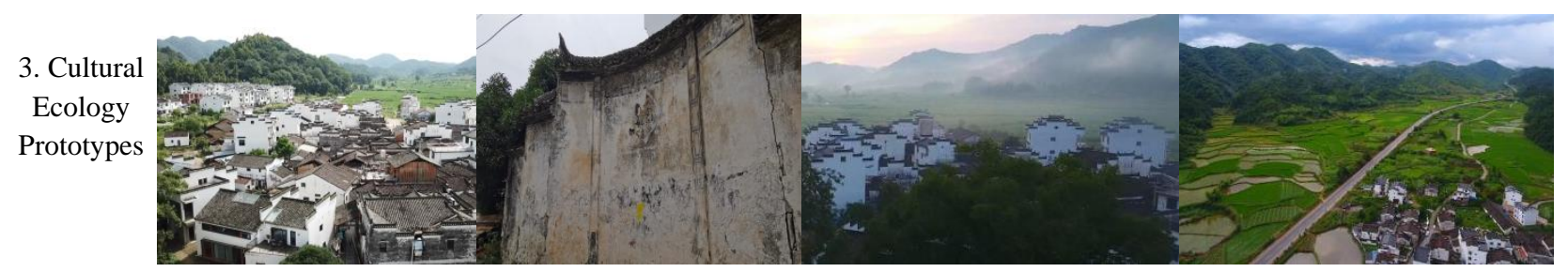

4.

Ecological Evolution

5. Effect

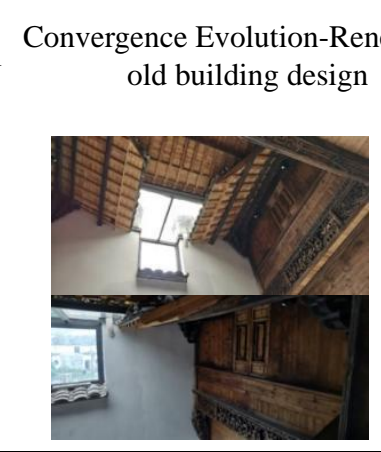
ceramic art culture

workshops, master studios, art lecture halls
wate

Types of crops grown
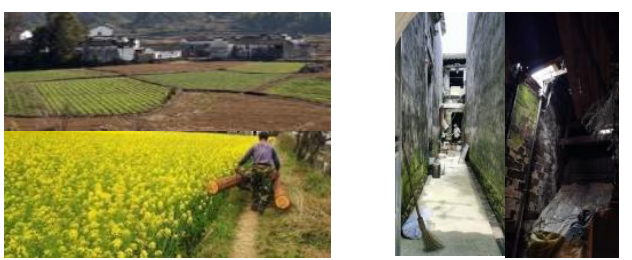

Mosaic

Evolution-Implantation of painting and art works
Opening of the hive hotel space next to the rice field
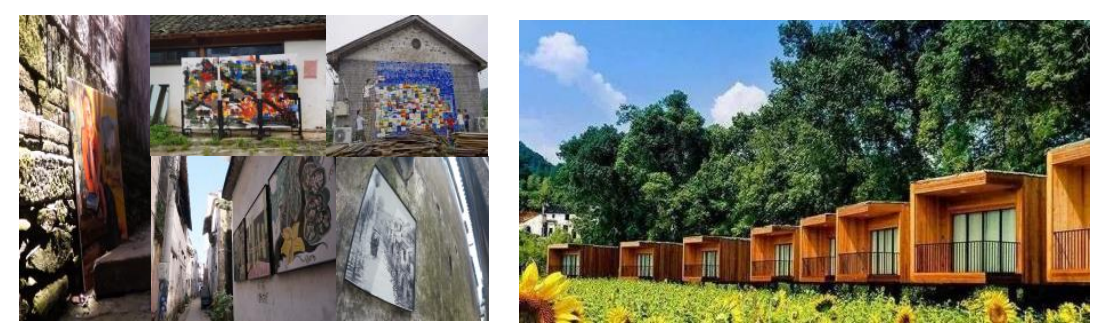
Li Chaoxian, author of Dalian University of Technology, mainly draws on the analysis elements of biological individuals in individual ecology to analyze the ecological analysis elements of architectural culture. Defining the ecological niche of architectural culture refers to the position and position of the building in the cultural ecological environment. And divide the four dimensions of architecture: natural environment dimension, man-made environment dimension, cultural environment dimension, and internal environment dimension. The greater the value of a certain latitude of its coordinate point, the stronger the influence of that dimension.

Based on the "niche" principle of ecology in WD.billings "plant and the Ecosystem", according to the four-dimension method of niche, the natural environment of Si Village is inspected: the terrain is flat and the surrounding is farmland. Cultural environment: Huizhou school and other traditional architectural culture, Jiangxi ceramic art culture. Man-made environment: catering, tourist reception, hotels and guesthouses, art workshops, master studios, art lecture halls. homeostasis: Jiangxi traditional village.

Ecological evolution is one of the important micro-level indicators among the seven indicators of ecological environment, ecological factors, ecological niches, limiting factors, ecological types, ecological adaptation, and ecological evolution. Based on Darwin's Evolutionary Biology, it is summarized into six biological evolution models, namely: Regressive Evolution, Aromorphosis, Convergence Evolution, Divergence Evolution, Gerontomorphosis, Mosaic Evolution. Summarize the evolutionary mode of the inspection division: Convergent Evolution-Traditional Old The architectural design is updated. Mosaic evolution-implantation of painting art works. Divergence and evolution-the opening of the hive hotel space next to the rice field.

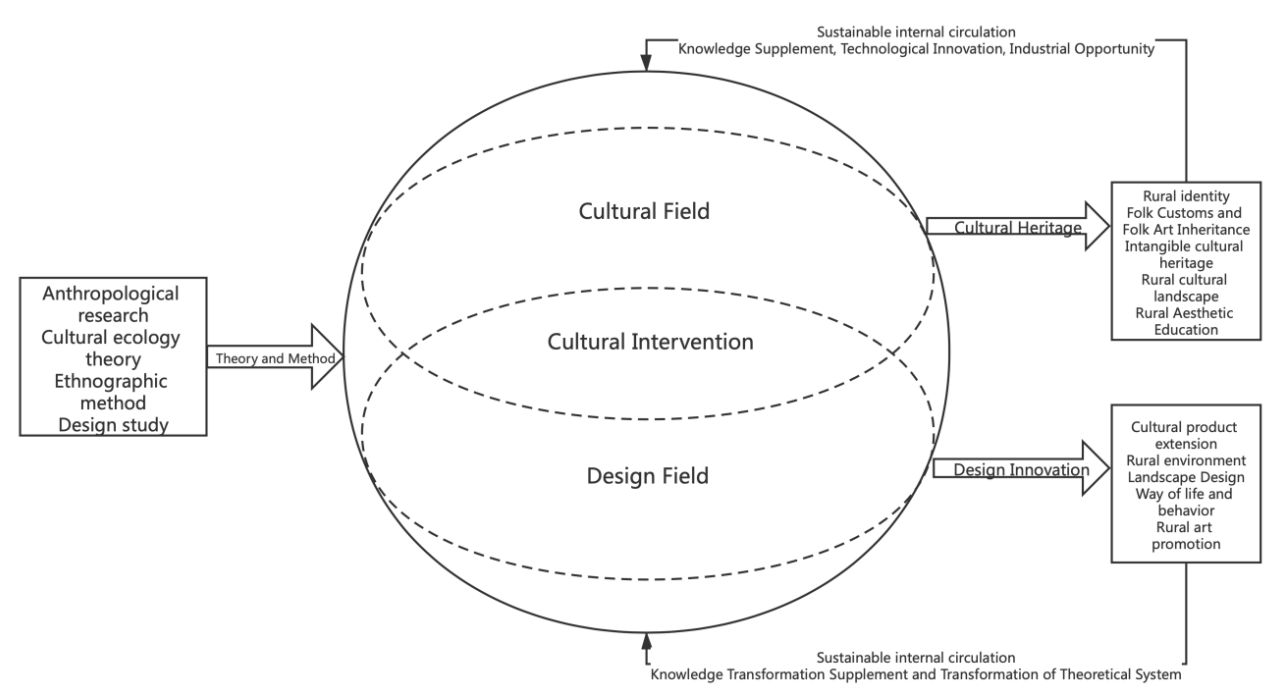

Figure 5. The overall system framework of cultural ecology of Xun Jiansi Village

The framework of the entire cultural ecology system consists of three parts. Firstly, it is introduced by anthropological research, cultural ecology theory, ethnographic method and design theory. The cultural field and the design field, and the art intervention plays a role in bonding the cultural field. The role of the domain and the design domain, and the formation of the cultural ecology as a whole. The cultural domain is passed through the rural regional identity, folklore and folk art inheritance, non-genetic inheritance, rural cultural landscape and rural aesthetic education promotion to achieve the rural cultural inheritance, and the design domain through cultural creation Product extension, improvement of rural environment, landscape design, lifestyle and behavior, and improvement of rural art achieve the purpose of design innovation, and ultimately the sustainable internal circulation will react to the overall cultural ecology.

\section{Conclusion}

This article is a theoretical analysis of the research feasibility of "village-cultural ecology", secondly, based on the concept and viewpoint of "cultural ecology", it reflects on the cultural erosion caused by the process of rural urbanization in my country, thirdly, analyzes contemporary design and rural Relevant ways of regional culture, finally, conduct cross-disciplinary research and analysis to determine the research ideas of the thesis, and conduct deduction research on the ecological expression method of rural design based on cultural ecology.

This article solves the problem of how to intervene in rural design through design art, public art, experimental art and other forms. In the exploration of this problem, extract the artistic elements and rural cultural resources involved in the countryside as the research core, and conduct research with two related contents, Carrying out art 
intervention rural design research expects to reshape the regional characteristics and contribute to the construction of Chinese beautiful countryside.

\section{References}

Bartley, D. D., \& Billings, W. D. (1971). Plants, Man and the Ecosystem. The Journal of Applied Ecology.

Fei, X. T. (2016). Rural Reconstruction of Rural China. Beijing: Qunyan Publishing House.

Li, C. X. (2019). Research on architectural design methods based on cultural and ecological concepts. Dalian University of Technology.

Miyazaki, K., Zhang, F. C. (1990). Internally developed township construction. News of Wuxi University of Light Industry, (1), 102-106.

\section{Copyrights}

Copyright for this article is retained by the author(s), with first publication rights granted to the journal.

This is an open-access article distributed under the terms and conditions of the Creative Commons Attribution license (http://creativecommons.org/licenses/by/4.0/). 